\title{
Dekasseguis a as Penitenciárias: Pesquisando as Fronteiras Entre o Brasil e o Japão.
}

\section{Prisons and Dekasseguis: researching the borders between Brazil and} Japan.

\section{Dra. Letícia Núñez Almeida ${ }^{1}$; Jennifer da Silva Pereira ${ }^{2}$; Nathan Bueno Macêdo ${ }^{3}$; Agnes Félix Gonçalves ${ }^{4}$; Rafael Augusto Masson Rocha ${ }^{5}$.}

\author{
${ }^{1}$ Inalmeida@usp.br, Universidade Federal do Pampa, ${ }^{2}$ agnesfgoncalves@gmail.com, \\ Universidade Federal do Pampa; ${ }_{3}^{3}$ jen.jps@ @otmail.com, Universidade Federal do Pampa; \\ ${ }^{4}$ agnesfgoncalves@gmail.com, Universidade Federal do Pampa; ${ }^{5}$ rmassonrocha@gmail.com, \\ Universidade Federal do Pampa.
}

\begin{abstract}
Resumo
O trabalho aqui apresentado é parte de uma pesquisa em desenvolvimento cujo objetivo é identificar a atual conjuntura dos sistemas penitenciários brasileiro e japonês, buscando evidenciar as semelhanças e diferenças em ambos os países no que tange às estatísticas carcerárias, Direitos Humanos, estrangeiros reclusos, acordos binacionais e internacionais etc. Nesse sentido, o estudo possui caráter exploratório e visa apresentar alguns pontos sobre a presença dos estrangeiros que vivem nas penitenciárias brasileiras e japonesas, levando em consideração que grande parte dos estrangeiros residentes no Japão são brasileiros de origem japonesa (dekasseguis). Assim, o foco do paper é propôr uma comparação, ainda que de caráter embrionário, sobre as condições das populações carcerárias de estrangeiros no Brasil e no Japão.

Palavras-chave: Relações nipo-brasileiras, Dekasseguis, Sistemas Penitenciários.

Abstract

The work presented here is part of a research development aimed at identifying the current situation of Brazilian and Japanese prison systems, seeking to highlight similarities and differences in both countries with regard to prison statistics, human rights, foreign prisoners, binational agreements and International etc. In this sense, the study has exploratory and aims to present some points about the presence of foreigners living in the Brazilian and Japanese prison, taking into account that the majority of foreign residents in Japan are Brazilians of Japanese origin (dekasseguis). Thus, the focus of the paper is to propose a comparison, albeit in embryonic character, on the conditions of the prison populations of foreigners in Brazil and Japan.
\end{abstract}

Keywords: Japanese-Brazilian Relations, Dekasseguis, Prison Systems. 


\section{O sistema carcerário brasileiro nos dias atuais}

O modelo atual de presídio como local onde um indivíduo cumpre pena de detenção é baseado nos primeiros protótipos de prisões da Igreja nos Estados Unidos, onde ficavam reclusos os que eram considerados hereges ou que iam contra os valores cristãos, reservados o direito de somente ler a Bíblia (DIAS, F.C.). Sejam em masmorras ou em fortes, o condenado pela Igreja não tinha nenhuma chance de obter a liberdade novamente. Assim como a humanidade progride em ritmo aritmético, houve mudanças e melhoras significativa em relação aos presídios ao redor do mundo em comparação ao passado, bastando observar o Japão e países nórdicos, como a Noruega e Suécia, que servem de exemplos no mundo em relação aos seus sistemas carcerários.

Uma observação superficial à um presídio em qualquer região do Brasil ou de outros países latinos evidenciam as diferenças gritantes em relação à estrutura, gestão e política penitenciária.Um resquício da essência das primeiras prisões existentes no mundo cujo objetivo não era uma reintegração do preso à sociedade, mas sim uma exclusão e aprofundamento da marginalização do indivíduo.Estima-se que a população carcerária brasileira seja de 607.730 detentos com capacidade de abrigar apenas 376669 , ou seja, a ocupação total das prisões brasileiras beira $161,3 \%$ de sua capacidade total ${ }^{1}$. Constituindo assim o Brasil um dos países onde a massa carcerária toma proporções colossais de crescimento de $471 \%$ nas últimas duas décadas frente à apenas $30 \%$ de crescimento demográfico de acordo com os dados apresentados pelo Instituto Avante Brasil. Diversos fatores que podem ser enumerados contribuem para uma falência do sistema penitenciário brasileiro, entendimento populista-vingativo-midiático de punição (recorrendo pouquíssimas vezes às penas alternativas), segregação social no tocante ao contato com a Justiça, a ineficácia do sistema penitenciário em fazer distinções entre seus detentos (por idade, grau de periculosidade, crime, pena), violações de Direitos Humanos e as mazelas dos presídios brasileiros ${ }^{2}$.

Alguns dos principais problemas apontados por MT JR Penal (2009) penal dos presídios brasileiros em relação às suas gerências, estruturas e relação com os detentos são:

- Espaço físico inadequado;

- Atendimentos de saúdes insatisfatórios;

- Falta de acesso efetivo à Justiça ou Defensorias Públicas;

\footnotetext{
1 Dados de International Centre for PrisonStudies (ICPS) referentes ao ano de 2014.

2 O artigo Tuberculose no sistema prisional de Campinas aborda sobre as más condições de insalubridade nas penitenciárias brasileiras.
} 
- Tortura e maus-tratos, corrupção, negligência e outras ilegalidades praticadas pelos agentes públicos;

- Incapacidade da Segurança Pública em manter a ordem e aplicar a lei com rigor sem desrespeitar os Direitos Humanos dos apenados;

- Entrada de materiais proibidos nas penitenciárias e o Estado não consegue aplicar a tecnologia existente de forma a prevenir ou combater o crime.

Embora os problemas apontados serem uma parcela significativa dos dilemas carcerários, deve se ressaltar que o Brasil passa por um momento delicado onde apresenta uma queda de 19,3\% no número de escolas públicas e um aumento de $253 \%$ no número de prisões $^{3}$. Nota-se que a Lei de Execução Penal não é cumprida, a respeito de ser um texto legal reconhecido por atender os presos de forma integral, de modo a proporcionar-lhes caminhos dignos, nunca houve políticas públicas para a execução da mesma ${ }^{4}$.O incremento de prisões deve-se ao fato abordado anteriormente de que há um grande aumento da população carcerária cujo aparelho estatal não consegue aglutinar. De acordo com os dados apresentados pelo Banco Nacional de Mandados de Prisão (BNMP), se hoje o Brasil executasse todos os mandados de prisão pendentes, o sistema carcerário entraria em colapso e ruiria, uma vez que o Brasil possui 437 mil mandados de prisão a serem efetivados e isso representaria uma adição de $71 \%$ à atual população carcerária.

Além do fator de que a população presidiária seja um aspecto importante que ajuda a compreender o atual cenário do sistema carcerário, deve se levar em consideração que a reincidência dos detentos no Brasil é de suma relevância para compreender a dimensão dos efeitos de um sistema carcerário deficitário que transcende ao presídio e permeia toda a sociedade. Com a taxa de reincidência de 47,4\% dos detentos depreende-se que em sua totalidade de ex-detentos "reinseridos na sociedade"quase a metade acaba regressando aos presídios $^{5}$. Salientamos que há um equivoco ao considerar reinserção do detento na sociedade, tendo em vista que os presídios fazem parte da sociedade, a única reinserção possível de se falar seria no mercado de trabalho. Levando em consideração que parte dosex-detentos voltam a cometer crimes não são percebidos aos olhos da Justiça em adição aos reincidentes, a conclusão empírica que surge é que mais da metade das pessoas liberadas no Brasil permanecem desenvolvendo atividades ligadas a crimes.

\footnotetext{
3 Dados do Instituto Avante Brasil (iAB)referentes ao período de 1994-2009.

${ }^{4}$ Lei № 7.210 , de 11 de Julho de1984.

${ }^{5}$ Fonte: Estudio comparativo de lapoblacióncarcelaria PNUD (2013).
} 
Percebe-se que o princípio elementar do sistema carcerário encontra-se desvirtuado no Brasil, partindo do pressuposto que o papel da prisão é restituir, ressocializar e reeducar para que seja possível obter relações harmônicas entre o apenado e a sociedade, onde o mesmo possa usufruir de uma liberdade gozando de seus direitos mais básicos e seja afastado da criminalidade. Atualmente o sistema carcerário brasileiro não se dispõe a fazer um triagem de seus detentos, apesar de ser mínimo gera vastas consequências, pois detentos que cometeram crimes de pequena expressão que poderiam ser apenados com alguma medida socioeducativa e de fato não representam ameaça real à sociedade são alocados junto com detentos de alta periculosidade e que ostentam serem partes de organizações criminosas. Consequentemente, esses "detentos menores" sentindo a vulnerabilidade dentro do ambiente prisional acabarão se aliando aos "detentos maiores" entrando em alguma facção ou organização que lhes ofereçam segurança, em contrapartida os "detentos maiores" aliciarão os outros para crimes maiores e assim se perpetua o círculo vicioso dentro das penitenciárias no Brasil.

É atribuído ao Estado o dever de assegurar ao detento segurança e saúde enquanto estiver sobre sua custódia e em caso comprovado de danos materiais e/ou morais o Estado deve reparar e indenizar de acordo com o Art. 37, § 6 da Constituição Federal de 88. Entretanto as violações de Direitos Humanos causados pelos detentos e pelos próprios agentes penitenciários no Brasil mostra a carência e a culpa do Estado ao se romper vínculo com o $3^{\circ}$ Artigo da Declaração Universal dos Direitos Humanos, onde a prisão brasileira é palco das piores mazelas humanas. No Brasil cerca de 67,5\% dos detentos se sentem menos seguros e protegidos dentro do sistema penal do que no lugar onde viviam antes de ingressar para os presídios $^{6}$. As prisões brasileiras estão vendadas e até coniventes com torturas infligidas em seus custodiados, sendo que a ação de tortura corriqueiramente não parte somente dos próprios companheiros de cárcere, mas também dos agentes penitenciários em situações de castigo, sanções disciplinares ou após conflitos dentro do ambiente penitenciário, desta maneira constata que a Lei de Tortura Lei $n^{\circ}$ 9455/97 é improfícua dentro do sistema penitenciário brasileiro.

\section{Os estrangeiros presos no brasil}

Em 2013 o número de estrangeiros presos no sistema penitenciário brasileiro era de 3,3 mil detentos, representando uma fatia de $0,63 \%$ da população carcerária no mesmo

\footnotetext{
${ }^{6}$ Fonte:Estudio comparativo de lapoblacióncarcelaria PNUD (2013).
} 
período de acordo com DEPEN. No Brasil não há uma separação expressiva dentro do sistema carcerário entre detentos estrangeiros e brasileiros, sendo que apenas $9 \%$ das unidades prisionais dispõe de celas exclusiva para estrangeiros, estes sofrendo nas mesmas condições degradantes e nos mesmos ambientes apertados, evidenciando assim uma das falhas do Brasil na gerência dos detentos estrangeiros. Dados de um relatório produzido pelo Grupo de Trabalho Pessoas Estrangeiras Privadas de Liberdade apontaram as principais dificuldades elencadas pelos estrangeiros presos no Brasil, que estão disponíveis no Levantamento Nacional de Informações Penitenciárias da Infopen referentes ao período de 2014. Essas dificuldades são:

- Dificuldade de obtenção de livramento condicional e de progressão de regime;

- Dificuldade em receber visitação e manter contato com a família;

- Carência à assistência consular;

- Dificuldades relacionadas à barreira linguística;

- Falta de acompanhamento jurídico;

- Desconhecimento das regras disciplinares e do processo de execução penal. O Conselho Nacional de Justiça conjuntamente com o Ministério da Justiça implantaram o Sistema de Cadastro Nacional de Presos Estrangeiros que está hospedado no site do Ministério da Justiça e sendo gerido pelo DEEST $^{7}$ tem criado mecanismos para reunir os principais dados sobre o estrangeiro como suas informações pessoais, seus delitos, tramitação penal entre outras informações aqui no Brasil ${ }^{8}$. Entretanto, não se sabe como esses dados estão sendo cadastrados e se estes estão sendo aproveitados para ajudar os estrangeiros que cumprem pena no Brasil.

De acordo com o portal Jus Brasil, o crime mais habitual cometido por estrangeiros é o tráfico de drogas, regularmente nas condições de mulas, correspondendo a cerca de $90 \%$ dos delitos. De 109 nacionalidades diferentes como Bolívia, Nigéria, Paraguai, Peru, Espanha, Angola, Colômbia, África do Sul, Portugal, etc (MACHADO, V. G. e NETO, P. M. R. 2014). Observe a tabela abaixo:

\begin{tabular}{|c|c|c|}
\hline \multicolumn{3}{|c|}{ RELAÇÃO DE ESTRANGEIROS RESIDINDO E } \\
ESTRANGEIROS PRESOS NO BRASIL REFERENTE AOS ANOS \\
DE 2013-2014 \\
\hline País & $\mathrm{N}^{\circ}$ de imigrantes & $\mathrm{N}^{\circ}$ de presos \\
\hline
\end{tabular}

\footnotetext{
${ }^{7}$ Sigla para Departamento de Estrangeiros.

8 Endereço do site: http://presosestrangeiros.mj.gov.br
} 


\begin{tabular}{|c|c|c|}
\hline Portugal & 277.727 & 95 \\
\hline Japão & 91.042 & - \\
\hline Itália & 73.126 & 40 \\
\hline Espanha & 59.985 & 175 \\
\hline
\end{tabular}

Tabela elaborada pelos autores $^{9}$

Por ser um país de dimensões continentais, com climas variados, considerado multiétnico e com uma história de imigrações fomentadas pelas economias dos séculos XIX e XX, atualmente o Brasil abriga cerca de 940 mil imigrantes permanentes, com uma taxa expressiva de estrangeiros provenientes da Europa; tais como Portugal que colonizara inicialmente o Brasil, Itália com seus imigrantes vindos para trabalharem nas lavouras de café na região Sudeste e Sul e Espanha e por fim o representante asiático Japão, objeto desse estudo. O Japão é o segundo país com o maior número de imigrantes no Brasil,entretanto, não há registros de japoneses presos nas nossas penitenciárias, sendo colocados na categoria da raça amarela todo detento de origem asiática, o único dado encontrado até aqui é no ano de 2012 havia 2.314 detentos da raça amarela ${ }^{10}$. Confirmando o que se vêm sendo dito da dissociação do sistema penitenciário com os grupos sociais, suas etnias culturas, categorizar os japoneses como "amarelos" é privá-los de sua dignidade e de sua história aqui no Brasil. Diferente do que acontece no Japão em relação aos brasileiros, e que será abordado no próximo ponto.

\section{Dekasseguis e emigrantes brasileiros no japão}

A maior comunidade japonesa fora do Japão encontra-se atualmente no Brasil. Tal peculiaridade se dá pelas íntimas relações entre o Brasil e o Japão que teve seus primórdios com a assinatura do Tratado de Amizade, Comércio e Navegação de 1895 firmado em Paris e com o atracamento do Navio KassatoMaruno Porto de Santos em 1908 trazendo 781 japoneses.

Na década de 1980, com o boom migratório de descentes japoneses sentido BrasilJapão que buscavam num primeiro momento melhores condições de vida e com trabalhos de rápido retorno financeiro para ajudar os familiares que ficaram no Brasil. Considerando que o Brasil passava por um momento de fragilidade econômica e o Japão apresentava uma gloriosa ascensão capitalista, tal cenário possibilitou e serviu de catalisador da migração em massa.

9 Baseado nos dados disponíveis no artigo Presos Estrangeiros no Brasil e o Problema da Seletividade Penal e no site: http://www.terra.com.br/noticias/infograficos/estrangeiros-presos-nobrasil/

${ }^{10}$ Fonte: Mapa do Encarceramento. 
Considerando que o conceito surge de um jogo de palavras em japonês, os autores que pesquisam sobre dekasseguisBeltrão e Sugahara (2006) em sua obra conjunta Permanentemente Temporário: Trabalhadores Brasileiros no Japão expõem a origem da palavra dekassegui. Formada pela junção de dois kanjis ${ }^{11}$ que juntos significam trabalhar fora: Deru(出る- verbo sair) e Kasegu(稼ぐ- verbo trabalhar). Os autores em questão esclarecem que tal termo teve origem no norte do Japão, onde havia um fluxo migratório de trabalhadores temporários rumo àTōkyō visando melhores condições de vidas, para depois voltar as suas terras de origem. Depreende-se que amplamente era considerado dekassegui qualquer pessoa japonesa que migrava pela questão do trabalho sazonal. Atualmente o conceito Dekassegui transcende fronteiras e não se limita apenas ao solo nipônico. Devido ao fato que o Brasil possui a maior comunidade japonesa fora do Japão, o dekassegui a ser analisado é aquele brasileiro que possuem a denominação $i s s e i^{12}$, nissei $i^{13}$ ou sansei ${ }^{14}$. O indivíduo brasileiro que não tenham ascendência japonesa, porém decide ir ao Japão para trabalho, estudos ou viver com o cônjuge tambémserão considerados dekasseguis pelo fato do termo ser bastante abrangente nos dias atuais.

A autora Sasaki (2000) aborda que no início da onda de imigração dekassegui, o termo dekassegui carregou um significado negativo e pejorativo. Naquele período, o Japão passava por uma expansão industrial em grandes proporções e com um número limitado de japoneses aptos a oferecer suas mãos de obra para realizar tarefas árduas. Com isso, os brasileiros de ascêndencia japonesa que se aventuraram naquele período em busca de trabalho, foram facilmente inseridos no mercado de trabalho. Porém, os trabalhos disponíveis eram trabalhos que faziam parte de um grupo denominado pelos japoneses de 3K. Kitanai(污い- sujo), kiken(危険- perigoso) e kitsui(きつい- penoso) eram os tipos de empregos que os primeiros dekasseguis exerciam. Deve-se salientar que era vergonhoso naquele momento ser tachado de dekassegui no Brasil e perigoso ser tachado de dekassegui no Japão, tendo em vista que o dekassegui naquele período não possuía nenhum respaldo do governo japonês e o Japão apresentava certa deficiência em acolher com devida dignidade os seus imigrantes.

Houve uma progressão lenta e gradual nos processos de imigração de dekasseguis até os dias atuais. As mudanças devem-se ao fato de que houve um grande escoamento

\footnotetext{
11 Ideogramas da escrita japonesa, derivados da língua chinesa.

${ }^{12}$ Imigrante japonês.

${ }^{13}$ Filho de imigrante japonês.

${ }^{14}$ Neto de imigrante japonês.
} 
populacional de dekasseguis voltando ao Brasil devido a crise de 2008. Ao considerarmos o número de 175.410 brasileiros residentes no período de 2014, apresentando uma redução de $3,3 \%$ da população de brasileiros em relação à 2013 e o tamanho do pequeno território do arquipélago japonês nota-se a expressividade desta mudança ${ }^{15}$. Ou seja, neste momento o número de dekasseguis no Japão está diminuindo.

\section{DEKASSEGUIS E A CRIMINALIDADE NO JAPÃO}

No ano de 2013 os brasileiros foram responsáveis por 2.425 crimes e em uma grande parte do ano de 2014 por 1.619 de acordo com à Agencia Nacional de Polícia do Japão ${ }^{16}$. Apresentando uma redução de $33 \%$ num recorte de um ano, as autoridades policiais japonesas acreditam que o aminguamento da participação de brasileiros está diretamente associado ao retorno de dekasseguis ao Brasil que vem ocorrendo recentemente, como dito anteriormente decorrente da crise econômica de 2008 que afetou fortemente o Japão. Observe a tabela abaixo com o recorte temporal referente ao primeiro trimestre de 2014:

\begin{tabular}{|c|c|c|}
\hline \multicolumn{2}{|c|}{$\begin{array}{c}\text { DADOS DA AGENCIA NACIONAL DE POLÍCIA NO JAPÃO SOBRE } \\
\text { ESTRANGEIROS QUE MAIS COMETEM CRIMES NO JAPÃO NO } \\
\text { PRIMEIRO TRIMESTRE DE 2014 }\end{array}$} \\
\hline País & $\mathbf{N}^{\circ}$ de crimes & $\begin{array}{c}\mathbf{N}^{\circ} \text { de crimes cometidos por } \\
\text { menores de } 20 \text { anos }\end{array}$ \\
\hline Chineses & 2.644 & 43 \\
\hline Brasileiros & 1.108 & 39 \\
\hline Vietnamitas & 1.046 & 7 \\
\hline Coreanos & 484 & 36 \\
\hline Filipinos & 448 & 87 \\
\hline
\end{tabular}

Tabela elaborada pelos autores

O Brasil ocupava em 2014 o segundo lugar de crimes cometidos por estrangeiros no Japão totalizando 1.108 crimes, perdendo somente para a China com 2.644 crimes. Entretanto o Brasil lidera o ranking de crimes cometidos por jovens abaixo de 20 anos com $87 \operatorname{casos}^{17}$. Os principais crimes cometidos por brasileiros no Japão são arrombamentos de veículos (de acordo com a BBC Brasil foram 686 casos só em 2014), furtos (responsáveis por cerca de $20,3 \%$ do furtos cometidos por estrangeiros), roubos de autopeças e carros e raríssimos casos

\footnotetext{
${ }^{15}$ Números retirados do JORNAL NIPPAK(Jornal em português voltado para o público dekassegui). 16 Números retirados da BBC Brasil.

17 De acordo com dados da Agência Nacional de Polícia do Japão referentes ao primeiro semestre de 2014 disponíveis no Notícias Alternativa(Portal de notícias voltado para brasileiros residentes no Japão).
} 
de crimes hediondos. Há também uma relação entre o uso de drogas e associação ao crime organizado japonês, como explica Fujita(2012): "O crime organizado no Japão facilita o acesso para os usuários, você acaba consumindo drogas cada vez mais pesadas"(FUJITA, A. 2012). ${ }^{18}$

De acordo com o Portal NIPPOBRASIL há também registros de brasileiros envolvidos em gangues e até mesmo entrando em contato com a máfia japonesa Yakuza. Como medida para haver uma melhor comunicação com brasileiros, policiais japoneses estão recebendo curso de língua portuguesa. Como explicaKamiunten (2015): "Durante dois anos, de segunda a sexta, eles aprendem o nosso idioma, inclusive gírias e termos técnicos jurídicos"(KAMIUNTEN, M. 2015) ${ }^{19}$.

Dessa forma, a presença brasileira na criminalidade do Japão fez (e faz) com que o Estado japonês busque instrumentos para lidar com a alteridade presente nesse fenômeno, uma delas é proporcionando o ensino da língua portuguesa como ferramenta para compreender as nuancesdos processos sociais envolvendo os dekasseguis. Não apenas os criminais, mas os que envolvem outras questões na sociedade japonesa, como a inserção de filhos de brasileiros no sistema educacional japonês, construções de asilos específicos para dekasseguis, etc.

\section{SISTEMA PENITENCIÁRIO JAPONÊS E OS ESTRANGEIROS}

Por estar localizado no leste asiático, no coração das civilizações orientais, o Japão (assim como outros países da mesma região como China e as Coreias) as concepções acerca do indivíduo possuem viés que podem ser desconcertantes para as culturas ocidentais. De acordo com estatísticas retiradas do 平成23年版犯罪白書 ${ }^{20} \mathrm{e}$ do site NihonGo！Reflexões e Impressões sobre o Japão ${ }^{21}$ nota-se que o Japão possui uma alta taxa de condenação, devido ao fato de que os promotores possuem discricionariedade para decidir se acusa ou não algum indivíduo, contudo $90 \%$ dessas condenações são multas. Sendo assim, de todas as condenações apenas a parcela de $10 \%$ acabam em prisão, desses $10 \%$ de condenações $60 \%$

\footnotetext{
18 Reportagem disponível no endereço: http://www.bbc.com/portuguese/noticias/2012/09/120905_presos_japao_et.shtml ${ }^{19}$ Reportagem disponível no endereço: http://www.bbc.com/portuguese/noticias/2015/06/150518_decassegui_violencia_et_lab 20Transliteração: Heisei 23-nenbanhanzaihakusho .Disponíveis no site: http://hakusyo1.moj.go.jp/jp/58/nfm/mokuji.html 21 Disponível no endereço: https://eduardompa.wordpress.com/2012/11/24/justica-penal-no-japaosevera-ou-nao/
} 
são suspensas. Dos que são condenados à prisão, $80 \%$ tem a menor que três meses. Esse número expressa o porque da quantidade razoável abaixo da capacidade total de presos no Japão.

O diretor YutakaNagashima do Instituto de Pesquisa deCriminalidadedo Ministério da Justiça do Japão afirma que o sistema carcerário japonês mostra-se desumano aos olhos dos ocidentais (NAGASHIMA, Y. 2010). A principal divergência apontada frente aos outros sistemas penitenciários ao redor do mundo é o intuito inicial da busca do arrependimento do detento, ou seja, o objetivo primário não é a ressocialização do detento. Por ser uma sociedade fortemente honorífica (que é refletida inclusive no idioma), cuja integridade é o valor de maior prestígio, quando o detento é preso no Japão fica claro que o mesmo perde toda sua honra, sendo o arrependimento o meio mais eficaz para a posterior ressocialização. Lembrando que diferente dos presídios brasileiros os presídios japoneses são militares. De acordo com Nagashima(2010) “Além de dar o devido castigo em nome das vítimas, o período de permanência na prisão serve como um momento de reflexão no qual induzimos o preso ao arrependimento"(NAGASHIMA, Y. 2010)

Como em todo sistema penitenciário, quando alguém é preso no Japão logo lhe é informado sobre as regras de conduta do presídio, seu nome é substituído por um número (alguns estrangeiros presos no presídio de $F u c h u[$ localizado na região homônima]dizem que uma das coisas mais difíceis é decorar o próprio número na língua japonesa). No confinamento os detentos são primeiro classificados de acordo com gênero, nacionalidade, tipo de penalidade, duração da sentença, periculosidade, e do estado físico e de saúde mental. Eles são, então, colocados em programas especiais destinados a tratar as suas necessidades individuais.

\footnotetext{
"Supõe em privá-los em princípio de sua liberdade, logo, reduzir seus impulsos criminais e por ultimo, reinseri-los o melhor possível na sociedade (...) Nosso papel consiste em ajudá-los e nosso principal objetivo é que voltem a reincidir"(MATSUMOTO, T) $)^{22}$
}

O apenado se depara com muitas restrições, tais como não pode olhar diretamente nos olhos dos agentes penitenciário, não manter conversar com outros detentos durante as refeições (sendo que o detento tem que manter os olhos fechados até receber o comando de abrir para iniciar sua refeição, e lhe são reservados apenas 40 minutos para as refeições), não fumar entre outras diversas restrições. Em algumas prisões como a deFuchu são ofertados aos detentos três tipos de refeições: a refeição tipo A é destinado aos detentos que trabalham duro ou que passam muito tempo em pé, a refeição tipo B é destinado aos detentos que trabalham

\footnotetext{
22 Tradução dos autores
} 
sentados e a refeição tipo C é destinada a detentos que trabalham em suas celas. Estrangeiros que não estão acostumados à culinária japonesa ou que não podem comer arroz são lhe ofertados refeições a base de pão.

O cotidiano dos detentos no Japão inicia-se pela manhã às 6:50h, começa a exercer suas funções (mais comumente em confecções de móveis, brinquedos, carpintaria, costura, marroquinaria, preparação de automóveis, etc.) dentro do presídio às 8:00h, há um pausa para o almoço e logo depois o detento volta a trabalhar até às 16:00h e logo depois retorna a sua cela. Às 17:25h inicia a janta e encerra no início da noite às 20:00h onde o detento retorna a sua cela novamente. Com conversa extremante regrada, os detentos só tem a chance manter um diálogo com seus companheiros penitenciários quando estão reclusos nas celas. Durante o verão são ofertados dois banhos semanais enquanto no inverno só há um banho semanal (sendo que nos outros dias os detentos são limpos com toalhas úmidas). Todo detento japonês é obrigado a trabalhar, sentindo se integrado e com algum valor prestado à sociedade, de acordo com o Capítulo 7 do Livro de Regras do Detento de Fuchu todo detento é obrigado a trabalhar, pois é uma lei no Japão. ${ }^{23}$ Quando um detento comete algum ato indisciplinar a sanção disciplinar mais leve é a notificação oral, a sanção mais pesada o detento fica restrito à solitária sem direito de exercer qualquer função ou atividade dentro do presídio. Caso se torne recorrente um mesmo detento retornar à solitária várias vezes, lhe é amarrado seus braços às costas com tiras de couro, impedindo seus movimentos mais básicos, de maneira que o ato de se alimentar (através de uma tigela como um cachorro) e de fazer suas necessidades fisiológicas se torne extremamente frustrantes e humilhantes. Um dekassegui anônimo disse "Fui castigado e fiquei na solitária mais de seis vezes. Todas por não ter entendido as regras do lugar. Cheguei a cortar meu pulso num ato de desespero (...) aqui nesse lugar vou ter de ser forte se quiser sair saudável. Vi dois conterrâneos serem transferidos por terem ficado loucos"24

De acordo com a International Centre for PrisonStudies o Japão possui uma capacidade no seu sistema carcerário de abrigar 90.531 detentos. Operando apenas com 69,6\% da sua capacidade total háo número de 61.794 detentos em todo o sistema carcerário japonês. Apenas 5,8\% da população carcerária é estrangeira, em números exatos são 9.884 detentos. Diferente do sistema carcerário brasileiro que padece com a superlotação, o Japão

23 O documentário JAPÃO ATRÁS DAS GRADES - PRISÃO DE FUCHU aborda o cotidiano do Presídio Fuchu, que vão desde a gerência do sistema penitenciário até depoimentos de estrangeiros presos. Foi realizada uma busca doLivro de Regras do Detento de Fuchu(abordado nodocumentário) na língua japonesa e o mesmo não apresentou nenhum resultado.

24 Disponível no endereço:

http://www.bbc.com/portuguese/celular/noticias/2012/09/120905_presos_japao_et.shtml 
possui uma ótima margem de número de vagas e detentos (sendo 1,4 vagas para cada detento no Japão enquanto são0,6 vagas para cada detento no Brasil).

Dados da Agência Nacional de Polícia do Japãoapontam que a parcela de brasileiros atualmente presos no Japão são de 397 indivíduos. Apesar de ser um número relativamente baixo é de suma importância para análise da situação atual dos estrangeiros, principalmente dos brasileiros no sistema penitenciário japonês. No Japão é permitido no máximo 6 detentos por cela, enquanto os estrangeiros são alocados em celas individuais com televisões que passam vídeo-aulas de língua japonesa. Não há registros de violações de Direitos Humanos aos detentos brasileiros no Japão, só há reclamações de brasileiros afirmando que a restrição de utilizar a língua materna, sendo permitindo o uso apenas da língua japonesa, cujos detentos são obrigados a frequentarem aulas do idioma. Desde a prisão, julgamento até em visitas de parentes e amigos nos presídios no Japão detento demanda o uso de intérpretes (que são pagos pelos próprios detentos). Tal restrição afeta a conduta do detento dentro do presídio por não compreender as regras, sendo que o único contato que o detento tem com o mundo exterior é através de cartas, onde pode se expressar na língua materna. Escrevendo para a Embaixada brasileira, consulados, jornais da comunidade japonesa e até grupos de apoio para desabafar os maiores pedidos dos detentos são itens de higiene, roupas, livros e até dinheiro.

\section{Considerações finais}

No decorrer do processo de pesquisa exploratória sobre a conjuntura dos sistemas carcerários brasileiro e japonês, percebe-se que é extremamente árduo e laborioso fazer uma comparação entre os seus sistemas carcerários devido às discrepâncias que em torno da complexidade de questões envolvidas nos sistemas penitenciários de cada país. Devido às distâncias geopolítica, demográfica e cultural entre o Japão e o Brasil, torna-se fundamental desenhar fios condutores para análise comparativa dos sistemas penitenciários de ambos países, o que pretende-se desenvolver ao longo da pesquisa principal. Em um primeiro momento, as principais diferenças encontradasestão relacionadas às histórias de ambos os países, tendo em vista que o Brasil possui uma história recente, com uma colonização peculiar catalisadora das grandes desigualdades sociais, com economia sensível às adversidades internacionais, política externa reativa, com uma visão ocidental de Direitos Humanos sendo que no continente asiático a concepção de Direitos humanos assume outras características; em contrapartida o Japão possui uma história milenar que apesar de ser bastante honorífica, nas ultimas décadas tem minimizado suas desigualdades sociais, com uma economia fortalecida e atrelada aos Estados Unidos (sendo que influi bastante Soft Power estadunidense no Japão), política externa expressiva na Ásia Oriental, e com uma visão oriental dos Direitos Humanos 
onde o coletivo se sobrepõe ao individual. As imigrações japonesas no Brasil e as brasileiras no Japão ocorreram em períodos diferentes e com aspirações diferentes. Sendo assim a recepção e a implementação de políticas para o acolhimento do imigrante japoneses no Brasil poderia ser um fator que contribuísse para o inexistente número de japoneses presos aqui. Enquanto os primeiros dekasseguis que chegaram ao Japão viviam em condições marginais, assumindo trabalhos que os próprios japoneses não queriam exercer e cuja esses dekasseguis o governo japonês só começou a observar e implementar políticas públicas no início do século XXI poderia ser um fator que contribuísse para que os brasileiros fossem os segundos estrangeiros que cometam mais crimes no Japão.

As realidades vividas por estrangeiros no Brasil em quase nada se diferencia de um brasileiro na mesma prisão, sendo que em tese o estrangeiro demandaria mais atenção e cuidado, porém este vive as mesmas condições desumanas, com alimentações sem acompanhamento nutricional e em presídios lotados, padecendo a própria sorte sem sequer poder exercer alguma atividade produtiva ou que torne a pena um pouco menos maçante. Em contrapartida os detentos estrangeiros, apesar de possuírem uma estadia regrada e regimentada, tem acesso aos estudos do idioma japonês, trabalho à executar, alimentação balanceada e diferenciada, celas individuais com direito à televisão e com reclamações pertinentes somente à restrição do idioma materno. É evidente que enquanto no Brasil o detento é considerado marginal à sociedade, no Japão os detentos a todo o momento se sentem inseridos na sociedade com uma parte importante. Será que a eficiência do sistema carcerário japonês seja reflexo de uma sociedade notoriamente reconhecida pela educação e harmonia? Ou será fruto de uma sociedade que combate os problemas sociais pela raiz? Será que a ineficiência do sistema carcerário brasileiro seja reflexo da sociedade brasileira ou reflexo dos problemas sociais que são resolvidos apenas nas "pontas"? Se a rigidez penal no Japão seja uma das responsáveis pelo pela qualidade das penitenciárias, por que essa mesma rigidez não prospera no Brasil? Estas dubiedades como essa são que norteam o desenvolvimento do projeto em questão e que servem de base para futuras pesquisas cujas linhas de pesquisas englobem as relações nipo-brasileiras, sistema carcerário brasileiro e outras vertentes.

\section{REFERÊNCIAS}

ALVES , E. M. P. Justiça penal no Japão: severa ou não?, 2012. Disponível em: <https://eduardompa.wordpress.com/2012/11/24/justica-penal-no-japao-severa-ou-nao/>. Acesso em:13 de Julho de 2015 
CASTRO, J. Brasil tem 'fila' de 437 mil mandados de prisão, 2015. Disponível em: <http://oglobo.globo.com/brasil/brasil-tem-fila-de-437-mil-mandados-de-prisao-15452442>. Acesso em: 11 de Agosto de 2015

CNJ. Órgãos criarão banco de dados sobre estrangeiros presos, 2012. Disponível em: $<$ http://www.cnj.jus.br/noticias/cnj/58349-orgaos-criarao-banco-de-dados-sobre-estrangeirospresos>. 09 de Agosto 2015

DIAS, F. C. A pena de prisão frente à ressocialização. Disponível em: <http://www.ambitojuridico.com.br/site/index.php?n_link=revista_artigos_leitura\&artigo_id= 8455>. Acesso em: 04 de Junho de 2015

GOMES, L. F. e BUNDUNKY, M. C. Crescimento da população carcerária ultrapassa vertiginosamente da população, 2012. Disponível em:

$<$ http://institutoavantebrasil.com.br/crescimento-da-populacao-carceraria-ultrapassavertiginosamente-o-da-populacao-nacional/>. Acesso em: 09 de Agosto de 2015

GOMES, L. F. Suécia e Holanda fecham prisões. Brasil fecha escolas e abre presídios, 2013. Disponível em: <http://institutoavantebrasil.com.br/suecia-e-holanda-fecham-prisoesbrasil-fecha-escolas-e-abre-presidios/>. Acesso em: 20 de Julho de 2015

GOMES, L. F. Brasil: reincidência de até 70\%, 2014. Disponível em: $<$ http://institutoavantebrasil.com.br/brasil-reincidencia-de-ate-70/>. Acesso em: 20 de Julho 2015

GOMES, L. F. e BUNDUNKY, M. C. Brasil: campeão mundial em crescimento de preso, 2012. Disponível em: <http://institutoavantebrasil.com.br/brasil-campeao-mundial-emcrescimento-de-presos/>. Acesso em: 20 de Julho de 2015

G1. Cardozo diz que presídios do país são 'verdadeiras escolas do crime', 2015. Disponível em: <http://g1.globo.com/politica/noticia/2015/06/cardozo-diz-que-presidios-dopais-sao-escolas-do-crime.html >. Acesso em: 19 de Julho 2015

ICPS. Japan, 2014. Disponível em: <http://www.prisonstudies.org/country/japan>. Acesso em: 07 de Junho de 2015

JORNAL NIPPAKI. JAPÃO: Diminui número de brasileiros no Japão; Aichi ainda é a província de maior concentração, 2015. Disponível em:

$<$ http://www.portalnikkei.com.br/japao-diminui-numero-de-brasileiros-no-japao-aichi-aindae-a-provincia-de-maior-concentracao/>. Acesso em: 07 de Junho de 2015

JURISWAY. O planejamento estratégico nas políticas voltadas para o sistema prisional: a garantia do respeito à integridade física e moral dos custodiados, 2012. Disponível em: <http://www.jurisway.org.br/v2/dhall.asp?id_dh=7605>. Acesso em: 07 de Junho de 2015

KAWAGUTI, L. Brasil tem $\mathbf{4}^{\mathrm{a}}$ maior população carcerária do mundo e deficit de $\mathbf{2 0 0}$ mil vagas, 2012. Disponível em:

http://www.bbc.com/portuguese/noticias/2012/05/120529_presos_onu_lk.shtml. Acesso em: 14 de Julho de 2015 
MAEDA, M. Japão: brasileiros cometem 1.108 crimes, 2014. Disponível em: <http://www.alternativa.co.jp/Noticia/View/33695/Japao-brasileiros-cometem-1108-crimes>. Acesso em: 07 de Junho de 2015

MAEDA, M. Crescem crimes de menores brasileiros, 2014. Disponível em: <http://www.alternativa.co.jp/Noticia/View/33742/Crescem-crimes-de-menores-brasileiros>. Acesso em: 07 de Junho de 2015

TERRA. Legião estrangeira do crime no Brasil, 2015. Disponível em: <http://www.terra.com.br/noticias/infograficos/estrangeiros-presos-no-brasil/>. Acessoem: 16 de Julho de 2015

TOBACE, E. Policiais aprendem português para enfrentar criminalidade brasileira no Japão, 2015. Disponível em:

<http://www.bbc.com/portuguese/noticias/2015/06/150518_decassegui_violencia_et_lab>. Acesso em: 20 de Julho 2015

TOBACE, E. Proibidos de falar português, presos brasileiros no Japão recorrem a cartas, 2012. Disponível em:

<http://www.bbc.com/portuguese/noticias/2012/09/120905_presos_japao_et.shtml>. Acesso em: 08 de Junho. 2015

YOUTUBE, Japão atrás das grades - prisão de Fuchu1 DE 4. Disponível em: <https://www.youtube.com/watch?v=RZLGfUXU97s>. Acesso em: 08 de Junho. 2015

YOUTUBE, Japão atrás das grades - prisão de Fuchu2 DE 4. Disponível em: <https://www.youtube.com/watch?v=kAWAQkq7QpU>. Acesso em: 08 de Junho. 2015

YOUTUBE, Japão atrás das grades - prisão de Fuchu3 DE 4. Disponível em: <https://www.youtube.com/watch?v=128RoXwXUdc>. Acesso em: 08 de Junho. 2015

YOUTUBE, Japão atrás das grades - prisão de Fuchu4 DE 4. Disponível em: <https://www.youtube.com/watch?v=gwtcZoZtoKI>. Acesso em: 08 de Junho. 2015

ZH NOTÍCIAS. Relatório de direitos humanos destaca condições desumanas em delegacias e prisões brasileiras, 2014. Disponível em:

$<$ http://zh.clicrbs.com.br/rs/noticias/noticia/2014/01/relatorio-de-direitos-humanos-destacacondicoes-desumanas-em-delegacias-e-prisoes-brasileiras-4395858.html>. Acesso em: 03 de Julho. 2015

ウィキペディア,府中刑務所. Disponível em: 〈https://ja.wikipedia.org/wiki/府中刑務所〉. Acesso em: 09 de Junho de 2015

BATISTA, AnalíaSoria. Estado e controle nas prisões. Cad. $C R H$ [online]. 2009, vol.22, n.56, pp. 399-410.ISSN 1983-8239.

FURUKAWA, Nagashi. O PCC e a gestão dos presídios em São Paulo. Novos estud. CEBRAP [online]. 2008, n.80, pp. 21-41. ISSN 1980-5403.

LOURENÇO, L. C. e GOMES, G. L. R. (Org.) Prisões e punições no Brasil contemporâneo, Editora EDUFBA. Salvador- Bahia, 2013. 
MTJR PENAL, O sistema prisional brasileiro, online disponível em: $<$ http://portal.estacio.br/media/1597224/artigo\%20sistema\%20prisional\%20brasileiro\%20pse udonimo\%20mtjr\%20penal.pdf. > . Acesso em: 01 de Junho de 2015

MACHADO, A. E. B., SOUZA, A. P. R., SOUZA, M. C. Sistema penitenciário brasileiroorigem, atualidades e exemplos funcionais. Revista do Curso de Direito da Faculdade de Humanidades e Direito, 2013.

PNUD. Mapa do encarceramento- os jovens do Brasil, Brasília 2015.

DEPEN. Levantamento nacional de informações penitenciárias INFOPEN- JUNHO DE 2014. Ministério da Justiça, 2015.

MACHADO, V. G. e NETO, P. M. R. Presos estrangeiros no Brasil e o problema da seletividade penal. Derecho y Cambio Social, 2014.

BELTRÂO, K. I.,\& SUGAHARA, S. (2006). Permanentemente temporário: dekasseguis brasileiros no Japão . R. Bra. Est. Pop. p. 61-85.

OLIVEIRA, Helenice Bosco de and CARDOSO, Janaina Corrêa. Tuberculose no sistema prisional de Campinas, São Paulo, Brasil. Rev PanamSaludPublica [online]. 2004, vol.15, n.3, pp. 185-193. ISSN 1020-4989.

SASAKI, E. M. (2000).Dekasseguis: trabalhadores migrantes nipo-brasileiros. TEXTOS NEPO. 